\title{
Pleural diseases related to metastatic malignancies
}

\author{
S.A. Sahn
}

Pleural diseases related to metastatic malignancies. S.A. Sahn. CERS Journals Ltd 1997 ABSTRACT: Pleural effusions associated with malignancy (either malignant or paramalignant) pose diagnostic and therapeutic dilemmas for the clinician. This article reviews the common causes of malignant and paramalignant pleural effusions, pathogenesis, clinical presentation, chest radiography, pleural fluid characteristics, diagnosis, prognosis, and treatment.

Talc, used either by poudrage or slurry, is the most effective agent used for pleurodesis. Talc, which needs to be sterilized, has no clinically important immediate, short-term or long-term adverse effects.

Eur Respir J 1997; 10: 1907-1913.

A malignant pleural effusion is diagnosed when exfoliated malignant cells are found in pleural fluid or when malignant cells are seen in pleural tissue obtained by percutaneous pleural biopsy, thoracoscopy, thoracotomy, or at autopsy. Some patients with malignancy have pleural effusions and no direct pleural involvement with tumour, and no other cause for the effusion can be found; I term these "paramalignant effusions" (table 1) [1]. Lymphatic obstruction is the most common cause of a paramalignant effusion and the predominant mechanism for the accumulation of large volumes of fluid in malignancy $[2,3]$. Other local effects of the tumour causing a paramalignant effusion are bronchial obstruction, with either
Correspondence: S.A. Sahn, Division of Pulmonary and Critical Care Medicine, Medical University of South Carolina, Charleston, South Carolina 29425-2220, USA

Keywords: Cancer, lung cancer, malignant effusion, paramalignant effusion, talc pleurodesis

Received: March 271996

Accepted after revision August 261996

Table 1. - Causes of paramalignant pleural effusions

pneumonia or atelectasis, and trapped lung. Effusions can result from systemic effects of the tumour and adverse effects of therapy.

Establishing the diagnosis of a malignant pleural effusion from lung cancer signals incurability, and a malignant effusion from a non-lung primary is a manifestation of far-advanced disease and is associated with limited survival [4].

\section{Malignancies associated with pleural effusions}

Carcinoma of any organ can metastasize to the pleura. However, carcinoma of the lung is the most common

\begin{tabular}{|c|c|}
\hline Cause & Comment \\
\hline \multicolumn{2}{|l|}{ Local effects of tumour } \\
\hline Lymphatic obstruction & Predominant mechanism for pleural fluid accumulation \\
\hline Bronchial obstruction with pneumonia & Parapneumonic effusion; does not exclude operability in lung cancer \\
\hline Bronchial obstruction with atelectasis & Transudate; does not exclude operability in lung cancer \\
\hline Trapped lung & Transudate; due to extensive tumour involvement of visceral pleura \\
\hline Chylothorax & Disruption of thoracic duct; lymphoma most common cause \\
\hline Superior vena cava syndrome & Transudate; due to increased systemic venous pressure \\
\hline \multicolumn{2}{|l|}{ Systemic effects of tumour } \\
\hline Pulmonary embolism & Hypercoagulable state \\
\hline Hypoalbuminaemia & Serum albumin $<1.5 \mathrm{~g} \cdot \mathrm{dL}^{-1}$; associated with anasarca \\
\hline \multicolumn{2}{|l|}{ Complications of therapy } \\
\hline \multicolumn{2}{|l|}{ Radiation therapy } \\
\hline Early & Pleuritis 6 weeks to 6 months after radiation completed \\
\hline Late & Fibrosis of mediastinum \\
\hline & Constrictive pericarditis \\
\hline & Vena caval obstruction \\
\hline \multicolumn{2}{|l|}{ Chemotherapy } \\
\hline Methotrexate & Pleuritis or effusion; \pm blood eosinophilia \\
\hline Procarbazine & Blood eosinophilia; fever and chills \\
\hline Cyclophosphamide & Pleuropericarditis \\
\hline Mitomycin & In association with interstitial disease \\
\hline Bleomycin & In association with interstitial disease \\
\hline
\end{tabular}

Previous articles in this series: No. 1: G. Miserocchi. Physiology and pathophysiology of pleural fluid turnover. Eur Respir J 1997; 10: 219-225. No. 2: R.W. Light. Diagnostic principles in pleural disease. Eur Respir J 1997; 10: 476-481. No. 3: G.T. Kinasewitz. Transudative effusions. Eur Respir J 1997; 10: 714-718. No. 4: J. Ferrer. Pleural tuberculosis. Eur Respir J 1997; 10: 942-947. No. 5: H. Hamm, R.W. Light. Parapneumonic effusion and empyema. Eur Respir J 1997; 10: 1150-1156. No. 6: G. Hillerdal. Chylothorax and pseudochylothorax. Eur Respir J 1997; 10: 1157-1162. No. 7: F.M.N.H. Schramel, P.E. Postmus, R.G.J.R.A. Vanderschueren. Current aspects of spontaneous pneumothorax. Eur Respir J 1997; 10: 1372-1379. No. 8: F. Rodriguez-Panadero, V.B. Antony. Pleurodesis: state of the art. Eur Respir J 1997; 10: $1648-1654$ 
Table 2. - Causes of malignant pleural effusions*

\begin{tabular}{lrr}
\hline Tumour & $\mathrm{n}$ & $\%$ \\
\hline Lung & 641 & 36 \\
Breast & 449 & 25 \\
Lymphoma & 187 & 10 \\
Ovary & 88 & 5 \\
Stomach & 42 & 2 \\
Unknown primary & 129 & 7 \\
Other causes & 247 & 14 \\
\hline
\end{tabular}

*: $\mathrm{n}=1,783$. Combined data from nine series.

malignancy to invade the pleura and produce malignant and paramalignant effusions (table 2) $[2,5,6]$. Carcinoma of the breast is second in incidence and, in some series, exceeds lung cancer [7]. After lung and breast cancer, the frequency declines markedly, with ovarian and gastric cancer representing $\leq 5 \%$ of malignant pleural effusions [2]. Lymphoma accounts for approximately $10 \%$ of all malignant pleural effusions, and is the most common cause of chylothorax. Carcinomas of the lung, breast, ovary and stomach, and lymphomas account for about $80 \%$ of all malignant pleural effusions. In approximately $7 \%$ of patients with malignant pleural effusions, the primary site is unknown when the diagnosis is first established.

\section{Pathogenesis}

An important feature of the parietal pleura is lymphatic stomata, i.e. openings between parietal pleural mesothelial cells [8]. The stomata and their associated lymphatic channels form lymphatic lacunae immediately beneath the mesothelial layer. The lacunae coalesce into collecting lymphatics, which join the intercostal trunk vessels, with flow directed mainly toward the mediastinal lymph nodes. The lymphatic system of the parietal pleura plays a major role in the resorption of pleural liquid and proteins [9]. Interference with the integrity of the lymphatic system anywhere between the parietal pleura and the mediastinal lymph nodes can result in a pleural effusion. Autopsies have indicated that impaired lymphatic drainage from the pleural space is the predominant mechanism for the accumulation of fluid associated with malignancy: a strong relationship was found between carcinomatous infiltration of the mediastinal lymph nodes and the occurrence of pleural effusion [2, 3]; in contrast, no relationship was found between the extent of pleural involvement by metastasis and the occurrence of pleural effusion [3]. Further support for this mechanism is provided by the observation that pleural effusions do not generally develop when the pleura is involved by sarcoma because of the characteristic absence of lymphatic metastases.

A bloody, malignant pleural effusion can result either from direct invasion of blood vessels, occlusion of venules, tumour-induced angiogenesis, or increased capillary permeability due to vasoactive substances $[3,10]$. Malignant pleural effusions usually contain a large number of morphologically normal lymphocytes, usually in the $50-70 \%$ range, but less than is seen in tuberculous pleurisy $(>90 \%)$ [11]. Although the reason for the lymphocytosis is not clear, these lymphocytes are predo- minantly T-lymphocytes that appear to play a role in the local defence against tumour invasion of the pleural cavity [12]. The percentage of mesothelial cells in malignant effusions is variable [10]. An abundance of mesothelial cells occurs early in the course of pleural infiltration, before pleural fibrosis and marked infiltration with tumour; in more advanced stages of pleural metastasis, fewer mesothelial cells are seen.

Postmortem studies have provided valuable insight into the pathogenesis of pleural metastases [3]. Parietal pleural involvement in lung cancer results either from neoplastic spread across the pleural cavity from visceral pleural sites along pleural adhesions that are either preformed or secondary to the malignant process, or from the attachment of exfoliated cells from the visceral pleura. The pathogenesis of visceral pleural metastasis in lung cancer appears to be through pulmonary artery invasion and embolization. Adenocarcinoma of the lung is the most common cell type to involve the pleura because of its peripheral location and spread by contiguity, and its propensity to invade the vasculature $[2,6]$. Bilateral pleural metastases in lung cancer are usually associated with hepatic involvement, with haematogenous spread to the contralateral lung [3].

Pleural metastases from primary sites below the diaphragm are generally a manifestation of a tertiary spread from established liver metastases [3]. Two mechanisms are operative in breast cancer with chest wall lymphatic invasion resulting in an ipsilateral effusion, and hepatic spread with bilateral or contralateral disease [13].

At diagnosis, pleural effusions are rare in Hodgkin's disease but not infrequent in non-Hodgkin's lymphoma [14-16]. Pleural effusions can be found in previously untreated patients with non-Hodgkin's lymphoma, even in the absence of detectable intrathoracic lymphadenopathy, and may be the only radiographic manifestation of the disease [15]. Lymphomatous invasion of the pleura appears to be an uncommon and late finding in Hodgkin's disease, but is commonly seen in non-Hodgkin's lymphoma [17, 18]. As Hodgkin's disease progresses, the incidence of pleural effusion increases and approaches $30 \%$. At autopsy, a 30-60\% incidence of pleural effusion and a 7-30\% incidence of pleural nodular infiltrative lesions has been noted [19]. Whilst pleural effusion in lymphoma can be due either to impaired lymphatic drainage due to mediastinal adenopathy, pleural or pulmonary infiltration, or to thoracic duct obstruction, impaired lymphatic drainage appears to be the primary mechanism in Hodgkin's disease and direct pleural infiltration the predominant cause in non-Hodgkin's lymphoma [20].

\section{Clinical presentation}

Patients with carcinoma of the pleura most often present with symptoms attributable to a large pleural effusion, dyspnoea on exertion, and cough [2]. The presence and degree of dyspnoea depend on the size of the effusion and the patient's underlying pulmonary function. A therapeutic thoracentesis results in relief of dyspnoea in most patients. However, the volume of pleural fluid removed at thoracentesis does not correlate with the change in lung volume. The increase in total lung 
capacity (TLC) approximates to a third of the volume of fluid removed, while the forced vital capacity (FVC) increases by about a half of the TLC [21]. Indeed, the mechanism of dyspnoea caused by a large pleural effusion appears to be multifactorial in origin, probably entailing a decrease in the compliance of the chest wall, contralateral shift of the mediastinum, and a decrease in ipsilateral lung volume, modulated by neurogenic reflexes from the lungs and chest wall. An obstructive pneumonitis, an endobronchial lesion that causes atelectasis, or an infiltrative malignant disease of the pulmonary parenchyma may also contribute to dyspnoea and cough.

Since malignant involvement of the pleura signifies far-advanced disease, these patients commonly have substantial weight loss and appear chronically ill. Chest pain can be present because of the involvement of the parietal pleura, ribs, or chest wall. However, in one large series of patients with metastatic carcinoma of the pleura, almost $25 \%$ were "asymptomatic" at the time of presentation [2]. In these patients, the malignant pleural effusion was first suspected on physical examination or diagnosed on routine chest radiograph; in almost $50 \%$ of patients, the pleural effusion was the first indication of cancer [2].

The respiratory symptoms of patients with pleural effusion due to lymphoma are indistinguishable in nature and frequency from those due to carcinoma [22]. About $20 \%$ of patients with lymphoma have no respiratory symptoms when the malignant pleural effusion is diagnosed.

Most patients with carcinoma of the pleura have evidence of a pleural effusion on physical examination when first seen by the physician [2]; physical signs of pleural effusion are to be expected since the volume of pleural fluid in most malignant effusions is greater than 500 $\mathrm{mL}$. Cachexia and lymphadenopathy are present in about a third of patients at presentation; ipsilateral chest wall tenderness and pleural friction rub are rare.

\section{Chest radiography}

A pleural effusion ipsilateral to the primary lesion is the rule in carcinoma of the lung [2]. When the primary site of the cancer is elsewhere than the lung, with the possible exception of breast cancer, there seems to be no ipsilateral predilection and bilateral effusions are common.

In three of four patients who present with carcinomatous involvement of the pleura, the pleural effusion is moderate to large, i.e. with volumes ranging 500-2,000 $\mathrm{mL}$ of fluid [2]. Ten per cent present with effusions of $<500 \mathrm{~mL}$ and $10 \%$ present with massive pleural effusions (complete opacification of the hemithorax). Seventy percent of patients with a massive pleural effusion will have a malignancy [23].

The finding of bilateral effusions and a normal heart size also suggests a malignant cause. Approximately 50\% of patients who present with this radiographic finding have a malignant effusion [24]; however, lupus pleuritis, hypoalbuminaemia, constrictive pericarditis, rheumatoid pleurisy, benign asbestos pleural effusion and cirrhosis must also be considered in the differential diagnosis.

If the mediastinum does not shift contralaterally in the face of a large pleural effusion $(>1,500 \mathrm{~mL})$, malig- nancy is almost always present and the prognosis is poor. The following diagnoses should be considered: 1) carcinoma of the ipsilateral main-stem bronchus resulting in atelectasis; 2 ) a fixed mediastinum due to malignant lymph nodes; 3) malignant mesothelioma (the radiodensity represents predominantly tumour with a small effusion); and 4) extensive tumour infiltration of the ipsilateral lung radiographically mimicking a large effusion. Interstitial infiltrates with effusions (lymphangitic carcinomatosis) and multiple nodules with effusions also suggest malignant disease.

\section{Pleural fluid characteristics}

Malignant pleural fluid may be serous, serosanguinous, or grossly bloody. The red cell count usually ranges $30,000-50,000$ cells $\cdot \mathrm{uL}^{-1}[1]$. The number of nucleated cells in the pleural fluid is modest $\left(1,500-4,000\right.$ cells $\left.\mu \mathrm{L}^{-1}\right)$, and consists of lymphocytes, macrophages and mesothelial cells. In about half of malignant pleural effusions, lymphocytes predominate (50-70\% of nucleated cells) [11]. Malignant cells in pleural fluid are rare in some patients; in others, they constitute virtually the complete population [10]. Polymorphonuclear leucocytes usually represent $<25 \%$ of the cell population; but, rarely, when pleural inflammation is active, they predominate. Pleural fluid eosinophilia (eosinophils $>10 \%$ of total nucleated cells), common in bloody pleural effusions, is unusual $(5 \%)$ in malignant effusions [25].

Pleural fluid in carcinoma of the pleura is usually an exudate with a protein concentration of about $4 \mathrm{~g} \cdot \mathrm{dL}^{-1}$ (range 1.5-8.0 g.dL-1) [2]. It is often not appreciated that approximately $5 \%$ of malignant pleural effusions are transudates $[2,26]$. These transudates are due either to concomitant congestive heart failure, atelectasis from bronchial obstruction, or the early stages of lymphatic obstruction [20]. Since protein can exit from the pleural space only by the parietal pleural lymphatics, a finite period (weeks) is necessary for protein to accumulate (from the $1.5 \mathrm{~g} \cdot \mathrm{dL}^{-1}$ of normal pleural liquid) to a level of $>50 \%$ of the serum concentration. Chronic pleural effusions and those with a low pleural fluid $\mathrm{pH}$ and low glucose levels tend to have a higher total protein concentration, and are virtually never transudates. Sometimes, the total protein pleural fluid to serum ratio may be low, but the fluid qualifies as an exudate by lactic dehydrogenase (LDH) criteria alone [27].

In a third of patients with malignant pleural effusions at the time of diagnosis, the pleural fluid $\mathrm{pH}$ is low $(<$ 7.30 ), with values as low as 6.95; these values can be found in empyema fluid [4]. In these low $\mathrm{pH}$ effusions, the glucose concentration is also low $\left(<60 \mathrm{mg} \cdot \mathrm{dL}^{-1}\right.$, or the ratio of pleural fluid to serum glucose is $<0.5$ ), the lactate concentration is increased, the carbon dioxide tension $\left(\mathrm{PCO}_{2}\right)$ is high, and the oxygen tension $\left(\mathrm{PO}_{2}\right)$ is low [28]. On rare occasions, the glucose is as low as $5 \mathrm{mg} \cdot \mathrm{dL}^{-1}$; but, as a rule, the concentrations are in the range $30-55 \mathrm{mg} \cdot \mathrm{dL}^{-1}$ [26]. In clinical practice, either the $\mathrm{pH}$ or glucose can be measured, as a low value has prognostic, diagnostic, and therapeutic significance (see below).

These low $\mathrm{pH}$, low glucose effusions have usually been present for several months, and are associated with 
a large tumour burden and fibrosis of the pleura. The markedly abnormal pleura interferes with glucose transport from blood to pleural fluid; the glucose that does enter is metabolized by normal and malignant pleural cells to form $\mathrm{CO}_{2}$ and lactate. The abnormal pleural barrier impairs the efflux of these end products of glucose metabolism from the pleural space, resulting in pleural fluid acidosis [28]. About $10 \%$ of malignant pleural effusions have high amylase concentrations. The finding of a high level of salivary-like isoamylase in a patient without oesophageal rupture essentially establishes the diagnosis of malignancy, most commonly adenocarcinoma of the lung [29].

\section{Diagnosis}

Malignant pleural effusion can be diagnosed only by demonstrating malignant cells in pleural fluid or pleural tissue. Cytology is a more sensitive test for the diagnosis than percutaneous pleural biopsy, because pleural metastases tend to be focal and the latter is a blind sampling procedure $[6,30,31]$. The yield on either procedure increases as the disease becomes more advanced. However, the yield from pleural biopsy with proven malignant effusion averages $50-60 \%$ [6, 31]. It appears, based on thoracoscopy, that initial pleural metastases begin near the mediastinum and diaphragm; as the disease progresses, tumour spreads cephalad and costal [32]. With improved techniques, the yield from exfoliative cytology now approaches 90-95\% [6, 7, 30]. If the clinician suspects a malignant effusion, several hundred millilitres of fluid should be removed at the initial diagnostic thoracentesis. This manoeuvre will not improve the yield on the initial study but, if it is negative, a repeat procedure several days later may provide fluid with fewer degenerative mesothelial cells and freshly exfoliated malignant cells. Percutaneous pleural biopsy should be reserved for the second thoracentesis if the initial pleural fluid cytological examination is negative. If the second cytological examination and initial pleural biopsy are negative, a third cytological examination and second pleural biopsy soon after is not usually diagnostic.

There are several options for the patient with suspected malignancy and negative pleural fluid and pleural tissue examination. These include: observation for a few weeks with repeat studies; thoracoscopy [33, 34]; or open pleural biopsy. Before proceeding to more invasive procedures, other causes of an exudative pleural effusion need to be excluded. Tuberculous pleurisy should always be considered in the patient with a lymphocyte-predominant exudate, with or without a positive tuberculin skin test. The yield from pleural biopsy culture and histology, in conjunction with pleural fluid culture and sputum smear and culture, probably provides a bacteriological diagnosis in up to $90-95 \%$ of cases [20]. Even if diagnostic studies are negative, patients with a positive tuberculin skin test and an undiagnosed lymphocyte-predominant exudate should be treated for tuberculous pleurisy, because of the high risk (70\%) of developing active pulmonary or extrapulmonary tuberculosis within 5 yrs if untreated [35].

Bronchoscopy has a low diagnostic yield for an idio- pathic pleural effusion without parenchymal lesions on chest radiograph, ipsilateral mediastinal shift, or haemoptysis.

The value of computed tomographic (CT) examination of the chest in an undiagnosed exudative effusion is unknown. Empyemas have a characteristic appearance on contrast CT scan, showing parietal pleural enhancement in most cases [36]. In addition, empyemas show parietal pleural thickening, thickening of the extrapleural subcostal tissues, and increased attenuation of extrapleural fat. None of the above findings are present in patients with transudative effusions. On occasion, patients with malignant effusions can show findings similar to those with empyema; however, previous sclerotherapy may be a confounding factor. Other causes of pleural effusion, such as lymphangitic carcinomatosis and benign asbestos pleural effusion, can be suggested by chest CT findings.

If observation is the course undertaken, the clinician would expect a malignant pleural effusion to be stable or to progress, and a nonmalignant effusion to be stable or to regress over time. Failure to identify a malignant pleural effusion for several weeks is rarely a disservice to the patient who has incurable disease. Exceptions are those malignancies that tend to be responsive to therapy, such as breast cancer, prostate cancer, thyroid cancer, small cell lung carcinoma, germ-cell neoplasms, and lymphomas.

At present, pleural fluid determination of carcinoembryonic antigen, hyaluronic acid, and LDH isoenzymes have no absolute diagnostic value for malignancy. Electron microscopic examination of pleural fluid (in contrast to tissue) seems to offer little advantage over routine cytological examination. Chromosome analysis of pleural fluid may be helpful in the diagnosis of lymphoma, leukaemia and mesothelioma; however, it is expensive and not readily available [37].

\section{Prognosis}

The diagnosis of a malignant pleural effusion signals a poor prognosis. Patients with carcinoma of the lung, stomach and ovary tend to have a survival time of only a few months from the time that the malignant effusion is diagnosed; patients with breast cancer may survive longer, several months to years, depending on the response to chemotherapy [4]. Patients with lymphomatous pleural effusions tend to have survival times intermediate between those of breast cancer and other carcinomas.

When $\mathrm{pH}$ and glucose concentrations in the malignant pleural effusion are low $\left(7.30\right.$ and $<60 \mathrm{mg} \cdot \mathrm{dL}^{-1}$, respectively), the survival time is less (average 2 months) than in those with a normal $\mathrm{pH}$ and glucose (average 10 months) [4]. Thus, the $\mathrm{pH}$ and glucose in the pleural fluid provide helpful information with respect to a rational plan of palliative treatment.

A pleural effusion in the setting of lung cancer usually excludes operability; however, approximately 5\% of these patients have a paramalignant effusion or effusion from another cause, and may be operable and curable [5]. Thus, it is essential to establish the cause of the pleural effusion before deciding that the patient is no longer a candidate for curative surgery. 


\section{Treatment}

When the pleural effusion has been proved to be malignant or paramalignant and the patient is not a surgical candidate, the mode of palliative therapy should be contemplated, taking into account the patient's general condition, symptoms, and expected survival. Several management options are available (table 3). Asymptomatic patients need not be treated: many will develop progressive pleural effusions that will evoke symptoms and require therapy; but some will reach a steady state of pleural fluid formation and removal and not progress to a symptomatic stage. In the debilitated patient, in whom a short survival is expected on grounds of general health, extent of disease, and the biochemical characteristics of the pleural fluid, periodic therapeutic thoracentesis as an out-patient is often preferable to hospitalization for tube thoracostomy and intrapleural instillation of a chemical agent.

Pleural abrasion with or without pleurectomy is almost always effective in obliterating the pleural space and controlling a malignant pleural effusion. However, pleurectomy is a major surgical procedure associated with considerable morbidity and some mortality [38, 39]. Accordingly, this procedure is reserved for patients who are in good general condition, who are expected to have a reasonably long survival, and who have failed chemical pleurodesis.

In general, systemic chemotherapy is disappointing for the control of malignant pleural effusions. However, some patients with lymphoma, breast cancer, or small cell carcinoma [40] of the lung manifest a good response to chemotherapy. In patients with carcinoma of the breast, procurement of quantitative data about steroid receptors from a malignant pleural fluid can provide valuable information relating to the potential response to hormonal manipulation [41].

Table 3. - Management of malignant and paramalignant pleural effusions

\begin{tabular}{ll}
\hline Option & Comment \\
\hline Observation & $\begin{array}{l}\text { Asymptomatic; most will } \\
\text { progress and require therapy }\end{array}$ \\
Therapeutic thoracentesis & $\begin{array}{l}\text { Prompt relief of dyspnoea; } \\
\text { recurrence rate variable } \\
\text { May be effective in lymphoma, }\end{array}$ \\
Chemotherapy & $\begin{array}{l}\text { small cell lung cancer, breast } \\
\text { cancer }\end{array}$ \\
Mediastinal radiation may be \\
effective in lymphoma and with \\
lymphomatous chylothorax
\end{tabular}

As a rule, radiation of the hemithorax is contraindicated in malignant pleural effusions from lung cancer, since the adverse effects from radiation pneumonitis outweigh possible benefits of therapy. However, when involvement of mediastinal nodes predominates, radiotherapy may be helpful in patients with lymphoma [42], or small cell carcinoma of the lung.

The most cost-effective method for controlling a malignant pleural effusion is chest tube drainage and intrapleural instillation of a chemical agent. A number of antineoplastic and non-antineoplastic chemical agents have been used for pleurodesis, with variable success. Currently, the most successful and widely-used agents include talc by poudrage or slurry, the tetracyclines (minocycline and doxycycline), and bleomycin [43]. Talc by either poudrage or slurry has been shown by numerous investigators to have a success rate of $>90 \%$ [43-45]. In direct comparisons with tetracycline and bleomycin, talc has been shown to be more effective. Furthermore, talc is readily available, inexpensive, and, when used in the proper doses, has minimal adverse effects [44]. When used as a slurry through a chest tube, talc is less expensive than the tetracycline-like drugs, and substantially less expensive than bleomycin [43]. The degree of pain associated with talc has been variously reported from nonexistent to severe [43]. Fever following talc poudrage and slurry is common, occurring from $16-69 \%$ of the time [43]. Fever characteristically occurs 4-12 h following talc instillation, and may last for $72 \mathrm{~h}$.

Other complications that have been reported with talc include empyema, arrhythmia, and respiratory failure, including adult respiratory distress syndrome (ARDS) and pneumonitis [44]. It is doubtful that the method of administration (poudrage or slurry) plays a major role in the development of respiratory failure, although the dose may be important, as many reported patients had received $\geq 10 \mathrm{~g}$ of talc.

Talc that is used for pleurodesis is asbestos-free but sterility is not required by US Pharmacopea (USP) standards. Although talc is not packaged under sterile conditions by the manufacturer, limitation on the number of microorganisms is part of USP specifications, and total bacterial count should not exceed 500 bacteria. $\mathrm{g}^{-1}$. Unsterilized talc contains bacillus species, which are generally thought to be nonpathogenic [46]; however, clinically significant disease has been reported, primarily in immunocompromised hosts and intravenous drug abusers, but also in normal hosts. Sterilization by prolonged dry heat exposure, ethylene oxide gas and gamma irradiation are all effective [46].

Before instituting chest tube drainage for intrapleural instillation of a chemical agent, it is necessary to demonstrate that fluid removal improves dyspnoea. Determination of the FVC and $\mathrm{PO}_{2}$ during the first 12 $\mathrm{h}$ following therapeutic thoracentesis may be misleading. Some patients experience a considerable decrease in $\mathrm{PO}_{2}$ [47] and minimal improvement in pulmonary function [48] despite relief of dyspnoea.

Following the initial therapeutic thoracentesis, the recurrence rate and interval for return of symptoms should be noted. If recurrence is rapid, with return of dyspnoea, pleurodesis should be considered. If the expected survival is at least several months, the patient is not debilitated, and the pleural fluid $\mathrm{pH}$ is $\geq 7.30$, the 
patient is a good candidate for pleurodesis. However, it is useless to attempt to produce pleurodesis if the lung cannot be expanded fully, as with mainstem bronchial occlusion or trapped lung. Furthermore, demonstrating that pleural fluid $\mathrm{pH}$ is $<7.30$ not only suggests a short survival-time but also predicts a poor response to chemical pleurodesis $[4,45]$. A large tumour bulk involving the pleural surfaces, together with low $\mathrm{pH}$ and low glucose pleural effusions, is associated with diminished effectiveness of the chemical agent.

The technique used for intrapleural instillation of a chemical agent is critical for a good result. The pleural space needs to be drained as completely as possible, so that the agent instilled is not diluted and the pleural surfaces remain in close contact during the time of the initial inflammatory insult. This is best accomplished by tube thoracostomy. If the patient has a large or massive effusion, the fluid should be drained slowly over the first several hours; the chest tube should be clamped intermittently to lessen the likelihood of unilateral pulmonary oedema. The position of the chest tube should be checked by chest radiography and the patient positioned to provide optimal drainage. When the chest radiograph demonstrates that the effusion is absent or minimal and the lung is fully expanded (usually by $24 \mathrm{~h}$ following chest tube insertion), $5 \mathrm{~g}$ of talc in a slurry should be instilled into the pleural space. Following instillation, the tube should be clamped for $1 \mathrm{~h}$. Evidence using radiolabelled tetracycline instilled through a chest tube has demonstrated rapid and complete dispersion in the pleural space without repositioning of the patient [49]. The chest tube can be removed when drainage is $<150 \mathrm{~mL} \cdot$ day $^{-1}$, usually within 24-48 h. If a large volume of drainage persists, a repeat dose of talc should be instilled. With properly selected candidates and rigorously applied technique, the malignant effusion is controlled with talc slurry in $>90 \%$ of cases [44].

A further option available for the patient with an intractable, symptomatic malignant effusion, who cannot undergo or has failed pleurodesis, is a pleuroperitoneal shunt [50]. These shunts have been found to be safe and effective. The shunt may be particularly beneficial in refractory chylothorax, as it allows recirculation of chyle. Few complications have been associated with their placement, and they can be inserted in patients who are poor surgical candidates. With experienced operators, palliation is obtained in $80-90 \%$ of properly selected patients. The major problem has been shunt failure, which is most commonly due to clotting of the catheter. It is unknown whether patients who have experienced shunt occlusion are at greater risk for occlusion after a new shunt is placed.

\section{References}

1. Sahn SA. Malignant pleural effusions. Semin Respir Med 1987; 9: 43-53.

2. Chernow B, Sahn SA. Carcinomatous involvement of the pleura: an analysis of 96 patients. Am J Med 1977; 63: 695-702.

3. Meyer PC. Metastatic carcinoma of the pleura. Thorax 1966; 21: 437-443.

4. Sahn SA, Good JT Jr. Pleural fluid $\mathrm{pH}$ in malignant effusions: diagnostic, prognostic, and therapeutic implications. Ann Intern Med 1988; 108: 345-349.

5. Decker DA, Dines DE, Payne WS, Bernatz PE, Pairolero PC. The significance of a cytologically negative pleural effusion in bronchogenic carcinoma. Chest 1978; 74 : 640-642.

6. Hsu C. Cytologic detection of malignancy in pleural effusion: a review of 5,255 samples from 3,811 patients. Diagn Cytopathol 1987; 3: 8-12.

7. Sears D, Hajdu SI. The cytologic diagnosis of malignant neoplasms in pleural and peritoneal effusions. Acta Cytol 1987; 31: 85-97.

8. Wang N-S. The preformed stomas connecting the pleural cavity and the lymphatics in the parietal pleura. Am Rev Respir Dis 1975; 111: 12-20.

9. Staub NC, Wiener-Kronish JP, Albertine KH. Transport through the pleura: physiology of normal liquid and solute exchange in the pleural space. In: Chretien J, Bignon J, Hirsch A, eds. The Pleura in Health and Disease. New York, Marcel Dekker, 1985; pp. 169-193.

10. Spriggs AI, Boddington MM. The Cytology of Effusions. 2nd edn. London, William Heinemann, 1968.

11. Yam LT. Diagnostic significance of lymphocytes in pleural effusions. Ann Intern Med 1967; 66: 972-982.

12. Domagala W, Emeson E, Kass LG. Distribution of Tlymphocytes and B-lymphocytes in peripheral blood and effusions in patients with cancer. J Natl Cancer Inst 1978; 61: 295-300.

13. Fentiman IS, Millis R, Sexton S, Hayward JL. A pleural effusion in breast cancer: a review of 105 cases. Cancer 1981; 47: 2087-2092.

14. Blank N, Castellino RA. The intrathoracic manifestations of the malignant lymphomas and leukemia. Semin Roentgenol 1980; 15: 227-245.

15. Castellino RA, Bellani PF, Gasparini M, Musumeci R. Radiographic findings in previously untreated children with non-Hodgkin's lymphoma. Radiology 1975; 117: 657-663.

16. Fisher AMH, Kendall B, Van Leuven BD. Hodgkin's disease: a radiologic survey. Clin Radiol 1962; 13: 115127.

17. Jenkins PF, Ward MJ, Davies P, Fletcher J. NonHodgkin's lymphoma, chronic lymphatic leukemia, and the lung. Br J Dis Chest 1981; 75: 22-30.

18. Xaubet A, Diumenjo MC, Marin A, et al. Characteristics and prognostic value of pleural effusions in non-Hodgkin's lymphomas. Eur J Respir Dis 1985; 66: 135-140.

19. Wong RM, Grace WJ, Rottino A. Pleural effusions, ascites, pericardial effusions, and edema in Hodgkin's disease. Am J Med Sci 1963; 246: 678-682.

20. Sahn SA. The pleura: state of the art. Am Rev Respir Dis 1988; 138: 184-234.

21. Judson MA, Sahn MA. Pulmonary physiologic abnormalities caused by pleural disease. Semin Respir Med 1995; 16: 346-353.

22. Weick JK, Kiely JM, Harrison EG Jr, Carr DT, Scanlon PW. Pleural effusion in lymphoma. Cancer 1973; 31: 848-853.

23. Maher GG, Berger HW. Massive pleural effusion: malignant and nonmalignant causes in 46 patients. Am Rev Respir Dis 1972; 105: 458-460.

24. Rabin CB, Coleman NS. Bilateral pleural effusion and significance in association with a heart of normal size. J Mt Sinai Hosp 1957; 24: 45-53.

25. Adelman M, Albelda SM, Gottlieb J, Haponik EF. Diagnostic utility of pleural fluid eosinophilia. Am J Med 1984; 77: 915-920. 
26. Clarkson B. Relationship between cell type, glucose concentration, and response to treatment in neoplastic effusions. Cancer 1964; 17: 914-928.

27. Light RW, MacGregor MI, Luchsinger PC, Ball WC Jr. Pleural effusions: the diagnostic separation of transudates and exudates. Ann Intern Med 1972; 77: 507-513.

28. Good JT Jr, Taryle DA, Sahn SA. The pathogenesis of low glucose, low pH malignant effusions. Am Rev Respir Dis 1985; 131: 737-741.

29. Cramer MR, Saldana MJ, Cepero RJ, Pitchenik AE. High amylase levels in neoplasm-related pleural effusion. Ann Intern Med 1989; 110: 567-570.

30. Johnson WW. The malignant pleural effusion: a review of cytopathologic diagnoses of 584 specimens from 472 consecutive patients. Cancer 1985; 56: 905-909.

31. Prakash UBS, Reinman HM. Comparison of needle biopsy with cytologic analysis for the evaluation of pleural effusion: analysis of 414 cases. Mayo Clin Proc 1985; 60: $158-164$.

32. Canto A, Rivas J, Saumench J, Morera R, Moya J. Points to consider when choosing a biopsy method in cases of pleurisy of unknown origin. Chest 1983; 84: 176-179.

33. Boutin C, Viallat JR, Cargnino P, Farisse P. Thoracoscopy in malignant pleural effusions. Am Rev Respir Dis 1981; 124: 588-592.

34. Rusch VW, Mountain C. Thoracoscopy under regional anesthesia for the diagnosis and management of pleural disease. Am J Surg 1987; 154: 274-278.

35. Roper WH, Waring JJ. Primary serofibrinous pleural effusion in military personnel. Am Rev Respir Dis 1955; 71: 616-634.

36. Waite RJ, Carbonneau RJ, Valikian JP, Emali CB, Pezzella AT, Nash G. Parietal pleural changes in empyema: appearances at CT. Radiology 1990; 175: 145-150.

37. Dewald G, Dines DE, Weiland LH, Gordon H. Usefulness of chromosome examination in the diagnosis of malignant pleural effusions. N Engl J Med 1976; 295 : 1494-1500.

38. Martini N, Bains MS, Beattie EJ Jr. Indications for pleurectomy in malignant effusion. Cancer 1975; 35: 734-738.

39. Fry WA, Khandekar JD. Parietal pleurectomy for malignant pleural effusion. Ann Surg Oncol 1995; 2: 160-164.

40. Livingston RB, McCracken JD, Trauth CJ, Chen T. Isolated pleural effusion in small cell lung carcinoma: favorable prognosis. Chest 1982; 81: 208-211.

41. Levine MN, Young JE, Ryan ED, Newhouse MT. Pleural effusion in breast cancer: thoracoscopy for hormone receptor determination. Cancer 1986; 57: 324-327.

42. Bruneau R, Ruben P. The management of pleural effusions in chylothorax and lymphoma. Radiology 1965; 85: 1085-1092.

43. Walker-Renard PB, Vaughan LM, Sahn SA. Chemical pleurodesis for the treatment of malignant pleural effusions. Ann Intern Med 1994; 120: 56-64.

44. Kennedy L, Sahn SA. Talc pleurodesis for the treatment of pneumothorax and pleural effusion. Chest 1994; 106: $1215-1222$.

45. Sanchez-Armengol A, Rodriguez-Panadero F. Survival and talc pleurodesis in metastatic pleural carcinoma, revisited. Chest 1993; 104: 1482-1485.

46. Kennedy L, Vaughan LM, Steed LL, Sahn SA. Sterilization of talc for pleurodesis: available techniques, efficacy, and cost analysis. Chest 1995; 107: 1032-1034.

47. Brandstetter RD, Cohn RP. Hypoxemia after thoracentesis: a predictable and treatable condition. $\mathrm{J} \mathrm{Am} \mathrm{Med}$ Assoc 1959; 242: 1060-1061.

48. Brown NE, Zamal N, Aberman H. Changes in pulmonary mechanics and gas exchange following thoracentesis. Chest 1978; 75: 540-541.

49. Lorch DG, Gordon L, Wooten S, Cooper JF, Strange C, Sahn SA. The effect of patient positioning on the distribution of tetracycline in the pleural space during pleurodesis. Chest 1988; 93: 527-529.

50. Little AG, Ferguson MK, Golomb HM, Hoffman PC, Vogelzang NJ, Skinner DB. Pleuroperitoneal shunting for malignant pleural effusions. Cancer 1986; 58: 27402743. 